\title{
Evaluation of a Bioactive Glass Alloplast in Treating Periodontal Intrabony Defects
}

\author{
Marianne M.A. Ong, ${ }^{*}$ Robert M. Eber ${ }^{\dagger}$ Maria I. Korsnes,${ }^{\dagger}$ R. Lamont MacNeil, ${ }^{*}$ \\ Gerald N. Glickman, ${ }^{\S}$ Yu Shyr, and Hom-Lay Wang
}

THIS STUDY EVALUATED THE USE OF bioactive glass (BG) for repairing/regenerating periodontal intrabony defects. Fourteen systemically healthy patients participated. Each patient had 2 contralateral sites with $\geq 6 \mathrm{~mm}$ clinical probing depth and radiographic evidence of an intrabony defect. One defect was treated with flap debridement plus BG (test) and the other with flap debridement alone (control). Baseline measurements included gingival index (GI), plaque index (PI), position of the free gingival margin (S/FGM), clinical attachment level (CAL), probing depth (PD), and mobility. At the time of surgery and at surgical reentry (9 to 13 months later), hard tissue measurements included: stent to defect base, bone crest to defect base, and defect width at the bone crest. One-way repeated ANOVA was used to analyze the treatment effect. Friedman's test was used to detect any significant changes of GI, PI and mobility at different time periods (baseline, 3 months, 6 months, and reentry). For multivariate analysis, the random coefficients mixed effect model was applied to adjust the intra-correlation effect. Both treatments resulted in decreased PD and gain of CAL. These changes were only significant $(P<0.05)$ for the BG treated sites (PD reduction $=1.24 \pm$ $0.43 \mathrm{~mm}$, CAL gain $=0.87 \pm 0.38 \mathrm{~mm}$ ) from baseline. Defect fill was significant for test $(1.1 \pm 0.4 \mathrm{~mm})$ and control $(1.4 \pm 0.4 \mathrm{~mm})$ alike $(P \leq 0.01)$. Although BG treated sites had more PD reduction and CAL gain than debridement only controls, there were no statistically significant differences between groups for any parameter measured. Further studies are required to clarify the beneficial effects, if any, of BG alloplast in treating periodontal intrabony defects. J Periodontol 1998;69:1346-1354.

Key Words: Grafts/bone; periodontal diseases/therapy; glass, biologically active; periodontal regeneration; surgical flaps.

Many bone grafting materials have been developed and tested for use in periodontal regeneration. Autografts, allografts, and alloplasts are the major types of commonly used bone graft materials. ${ }^{1}$ Of the currently available bone graft materials, only autogenous bone grafts (autografts) are truly osteogenic. Autografts of cancellous bone may contain viable cells that can form new bone when implanted in a periodontal intrabony defect. ${ }^{2.3}$ Autografts,

\footnotetext{
*Currently, National Dental Centre Pte. Ltd., Singapore; previously, Department of Periodontics/Prevention/Geriatrics, School of Dentistry, University of Michigan, Ann Arbor, MI.

Department of Periodontics/Prevention/Geriatrics.

*Currently, University of Connecticut; previously, Department of Periodontics/Prevention/Geriatrics.

Department of Cariology, Restorative Sciences, and Endodontics.

"Division of Biostatistics, Department of Preventive Medicine, School of Medicine, Vanderbilt University, Nashville, TN.
}

however, are often impractical because a second surgical site is often needed and available quantities are limited.

Allografts, such as demineralized freeze-dried bone (DFDBA), have been an effective alternative to autogenous grafts. ${ }^{4,5}$ DFDBA contains no viable bone cells; therefore, it is not osteogenic. DFDBA contains bone morphogenic proteins (BMPs) that can, when implanted in a periodontal defect, induce the surrounding tissues to produce bone. ${ }^{6}$ Therefore, DFDBA is osteoinductive. DFDBA is widely used and has an exceptional safety record. ${ }^{7}$ Some patients, however, still choose not to have implants of DFDBA because it is procured from cadavers. Additionally, the osteoinductive properties of DFDBA can vary depending on the procurement and preparation procedures followed. ${ }^{8}$ Therefore, the quality of DFDBA may vary from bone bank to bone bank.

Alloplasts, or synthetic bone graft materials, can be 
made in unlimited quantities. This a distinct advantage over autografts and allografts. ${ }^{9}$ Unfortunately, alloplasts available until recently (e.g., hydroxyapatite and tricalcium phosphate) have yielded inconsistent clinical results and disappointing histological results, often evidenced by fibrous encapsulation of the graft particles. ${ }^{10-24}$ Alloplasts are osteoconductive; i.e., they act as a scaffold to support new bone growth but they neither generate new bone nor induce new bone formation.

Recent studies report that a newer ceramic alloplast, bioactive glass (BG), in addition to being osteoconductive, bonds directly to bone tissue. ${ }^{25.26}$ In the presence of body fluids, through a series of ion exchange reactions, BG forms a surface layer consisting of two parts: an inner silica $(\mathrm{Si}$ ) -rich layer and an outer calcium-phosphate (CaP) -rich layer. This CaP-rich layer is believed to encourage osteoblasts to deposit organic bone matrix. ${ }^{25,27}$ Ionic sites on collagen and mucopolysaccharides of the organic bone matrix cross-link with sites on the CaP-rich layer. This cross-linking achieves a bond between BG and the surrounding bone. ${ }^{28} \mathrm{BG}$ has been used to maintain alveolar ridges ${ }^{29-32}$ and to repair periodontal defects and bony lesions. ${ }^{33-37}$

Wilson and Law treated surgically created periodontal defects in monkeys with bioactive ceramic materials: tricalcium phosphate (TCP); hydroxyapatite (HA); and two compositions of $\mathrm{BG}\left(45 \% \mathrm{SiO}_{2}, 24.5 \% \mathrm{CaO}, 24.5 \%\right.$ $\mathrm{Na}_{2} \mathrm{O}, 6 \% \mathrm{P}_{2} \mathrm{O}_{5}$ and $43 \% \mathrm{SiO}_{2}, 14 \% \mathrm{CaO}, 13 \% \mathrm{CaF}_{2}, 24 \%$ $\left.\mathrm{Na}_{2} \mathrm{O}, 6 \% \mathrm{P}_{2} \mathrm{O}_{5}\right) .{ }^{34}$ After 9 months, both compositions of BG promoted bone regeneration and inhibited epithelial downgrowth. In contrast, TCP and HA treated sites healed with a long junctional epithelial attachment that was similar to the unfilled control defects. ${ }^{34}$

Schepers et al. treated 106 bone defects in 87 patients with BG implants. ${ }^{36}$ The BG had a narrow particle size range of 300 to $360 \mu \mathrm{m}$. The bone defects included apical resection areas, cystic lesions, extraction sockets, and alveolar ridge deficiencies. They reported that at 3 months, BG became fully solidified clinically and radiographically appeared to be integrated with bone tissue.

Schepers and Pinruethai also treated surgically created, ligature-induced periodontal defects in beagle dogs with either BG (particle size 300 to $360 \mu \mathrm{m}$ ) or porous HA. ${ }^{38}$ Both treatments resulted in reduced $\mathrm{PD}$ and gain of CAL. BG treated sites, however, showed a better gain of CAL $(1 \mathrm{~mm})$ when compared to HA treated sites $(0.25 \mathrm{~mm})$. Histologically, bone formed around the BG particles regardless of their location; however, bone only formed around HA particles that were close to the preexisting bone. ${ }^{38}$

More recently, Zamet et al. in a controlled clinical trial of 20 patients with 44 intrabony defects, reported that intrabony periodontal pockets treated with BG had significantly better radiographic density and volume than debridement only control sites. ${ }^{39}$ They also reported that there was a trend towards more PD reduction and CAL gain in the BG treated sites; however, the differences were not statistically significant.

Thus, studies indicate that BG shows promise for use in periodontal repair/regeneration. To date, there have been limited studies evaluating BG for use in the treatment of periodontal intrabony in humans. ${ }^{39}$ The results of these studies were inconclusive. Therefore, the purpose of this study was to evaluate bioactive glass as an alloplastic graft material for the repair of human periodontal intrabony defects.

\section{MATERIALS AND METHODS}

\section{Patient Selection}

Fourteen systemically healthy patients, 11 males and 3 females, ages 35 to 67 years (mean $=49.1$ years), participated in this study. All were patients of the Department of Graduate Periodontics at The University of Michigan, School of Dentistry. The Human Subject Review Committee of The University of Michigan approved the study protocol. Patients were enrolled in the study if they met the following criteria: 1) hygiene phase therapy had been completed (oral hygiene instruction, scaling and root planing, and possibly occlusal therapy) or the patient had received hygiene phase therapy in the past and was now in a periodontal maintenance program; 2) evidence of localized moderate to severe periodontitis; 3 ) two contralateral periodontal intrabony defects with probing depths $\geq 6 \mathrm{~mm}$; 4) radiographic evidence of an intrabony defect that measured at least $3 \mathrm{~mm}$ from the alveolar crest to the base of defect; 5) no antibiotic therapy in the past 6 months; 6 ) no periodontal surgery in the areas to be treated within the last 12 months; and 7) no known allergy to materials and drugs used or prescribed in this study, including silica products. All patients gave informed consent prior to entering the study.

\section{Measurements}

The following were recorded at baseline (time of surgery), at 3 months, at 6 months, and at 9 to 13 months after surgery: $\mathrm{PD}$; CAL; position of the free gingival margin (S/FGM); mobility; ${ }^{40}$ gingival index (GI); ${ }^{41}$ and plaque index (PI). ${ }^{42} \mathrm{PD}$ and CAL were measured with an automated probet set to a standardized force of 20 grams (Fig. 1). S/FGM was measured with a North Carolina 15 $\mathrm{mm}$ probe from a reference notch on a vacuum formed acrylic stent to the free gingival margin of the defect site. The stent also served as a reference for measuring CAL (Fig. 1). Vertical grooves in the stent aided in aligning the probe. A horizontal groove in the stent created a ledge that served as a reference point for taking measurements. The stent was not used to measure PD. PD measurements

"Florida Probe Co., Gainesville, FL. 


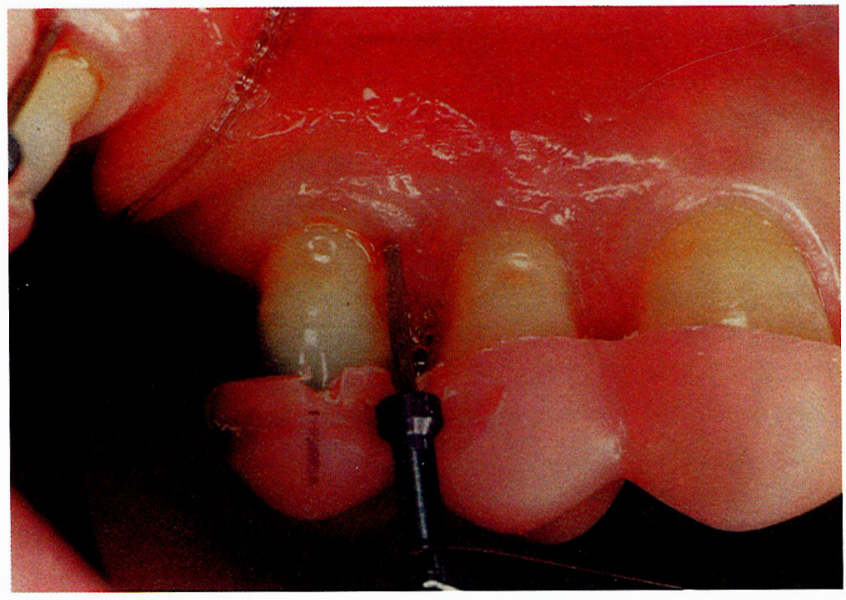

Figure 1. Demonstrates how clinical measurement, CAL, was taken from the surgical stent ledge and grooves.

were made from the gingival margin to the base of the sulcus/pocket. For interproximal PD and CAL measurements, the examiner angled the probe to measure the depth of the defect at the midpoint of the tooth faciolingually. Interproximal PD and CAL measurements were taken from the buccal and lingual aspects and then averaged to better represent the site. At 1,2, and 4 weeks after surgery, only GI and PI were recorded.

Hard tissue measurements were recorded at the time of surgery and at the 9 - to 13 -month reentry surgery. The measurements were taken after the defects had been debrided of all granulation tissue. Hard tissue measurements included: stent to base of defect (SB), crest of bone to base of defect $(\mathrm{CB})$, bucco-lingual (B-L) defect width at the alveolar crest, and mesio-distal (M-D) defect width at the alveolar crest. Stent to crest of bone (SAC) was calculated by subtracting CB from SB (Fig. 2). The automated probe with a standardized force of 20 grams was used to measure stent to base of bone defect (SB) (Fig.1). The North Carolina probe was used to record alveolar crest to the base of defect (deepest portion) using a groove on the stent as a reference point for site identification; BL horizontal defect width at the alveolar crest; and M-D horizontal defect width at the alveolar crest. Single site values were used for analyzing all hard tissue measurements.

Film holders with custom acrylic bite registration indices were used to take standardized periapical radiographs at baseline (prior to surgery), 6 months after surgery, and 9 to 13 months after surgery. ${ }^{44}$

One examiner (MIK) was calibrated prior to the study and made all measurements during the course of the study. The examiner was masked to the procedures performed.

\section{Surgical Protocol}

All surgical procedures were carried out from January 1996 to September 1996 in the Department of Graduate

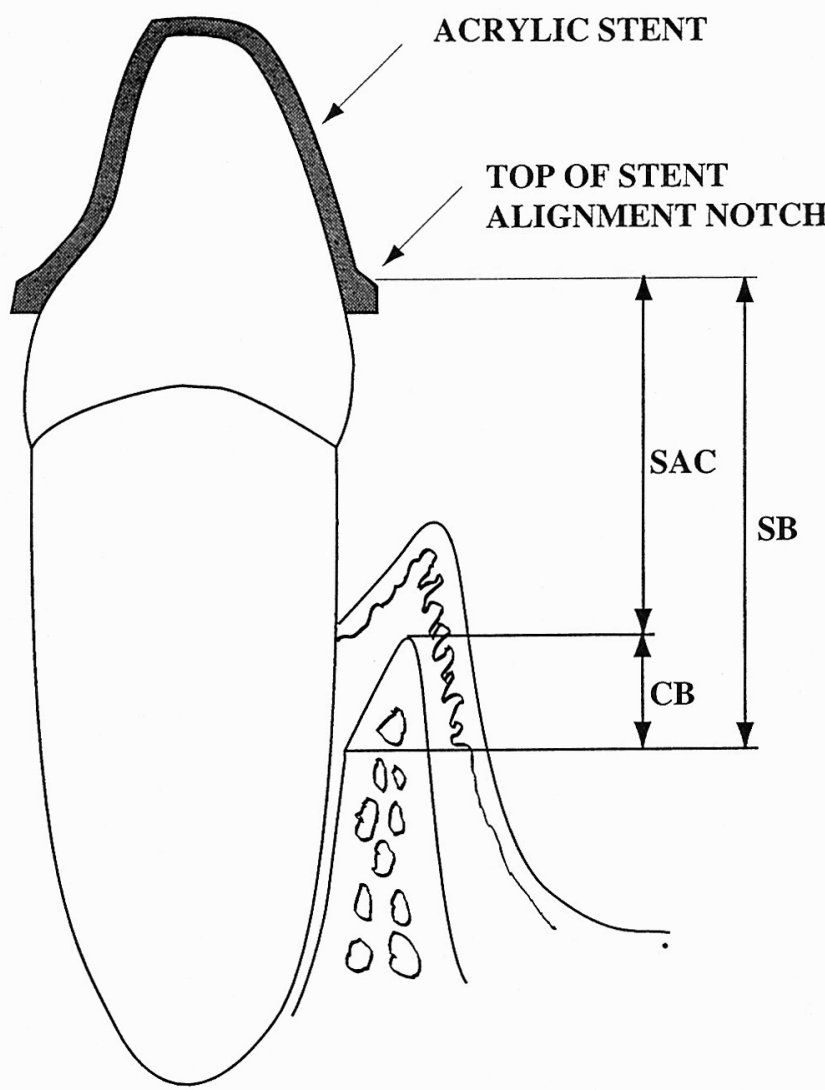

Figure 2. Hard tissue measurement method.

Initial measurements:

$S B=$ Stent to base of defect

$C B=$ Alveolar crest to base of defect

Arithmetic determinations:

$S A C=S B-C B$

Stent to alveolar crest initial

$\mathrm{SAC}^{1}=\mathrm{SB}^{1}-\mathrm{CB}$

Stent to alveolar crest at reentry

Defect fill $=\mathrm{SB}-\mathrm{SB}$

Base of initial defect to base of reentry defect

Crestal resorption $=\mathrm{SAC}^{\prime}-\mathrm{SAC}$

Reentry alveolar crest to initial alveolar crest

Reentry measurements (not pictured):

$S B^{1}=$ Alveolar crest to base of defect

$\mathrm{CB}^{1}=$ Alveolar crest to base of defect

Periodontics surgical clinic at The University of Michigan School of Dentistry. Graduate periodontic residents, including the primary investigator (MO), performed the surgeries. The primary investigator designed and performed all initial flap incisions. The primary investigator also supervised the debridement of defects, fill of test sites with $\mathrm{BG}$ and placement of sutures to ensure that each surgeon adhered to the study protocol. All surgeries were photodocumented by the primary investigator (MO).

Apart from graft placement, surgical procedures were identical for test and control sites. Following adequate local anesthesia, buccal and lingual intrasulcular incisions were made and full thickness flaps were elevated with care to preserve the interdental papillae. After debride- 
ment of the osseous defects, the root surfaces were scaled and root planed with ultrasonic and hand instruments to a smooth, hard consistency. When bleeding was not observed in the defect area, intramarrow penetration through the defect walls was performed with a $1 / 2$ round bur.

At the time of surgery, patients were randomly assigned to receive test or control treatments on the right or left side by drawing a coded paper from a paper bag. This was done to avoid operating bias (right versus left side). Surgeons filled the intrabony defects at the test sites to the level of the alveolar crest with BG (90 to $710 \mu \mathrm{m}$ particles)** that had been wetted with sterile water according to the manufacturer's directions. The control sites received no bone graft but were otherwise treated identically. Silk horizontal mattress sutures were used to close the defect sites. The remaining flap was sutured with interrupted 4-0 black silk sutures.

Patients received routine written and oral postoperative instructions. All patients were instructed to rinse with 1/ 2 ounce $0.12 \%$ chlorhexidine gluconate twice daily for a period of 2 weeks. After 2 weeks, patients used a cotton tip applicator to apply the chlorhexidine directly to the surgery sites twice daily. Patients resumed normal brushing and flossing 6 weeks after surgery. At that time they discontinued chlorhexidine use. No antibiotics were prescribed unless postoperative complications developed. The sutures were removed after 1 week. After surgery, patients were seen at 2 weeks, 4 weeks, 3 months, 6 months, and 9 to 13 months for tissue evaluation, plaque debridement, and oral hygiene review.

\section{Nine to 13 Months Reentry Surgery}

Reentry surgeries were performed 9 to 13 months after the initial surgery. Clinical measurements (GI, PI, PD, CAL, S/FGM, mobility) were recorded prior to reentry. After making sulcular incisions, full-thickness mucoperiosteal flaps were elevated to expose the previously treated test and control sites. Defect sites were debrided of all granulation tissue until firm, hard bone was reached. Clinical photographs and hard tissue measurements were taken as previously described. Osteoplasty was performed as needed to correct any residual osseous defects. Flaps were then replaced and sutured. Patients returned at 1 week for suture removal. All patients were placed on 3-month recall for supportive periodontal treatment.

\section{Statistical Analysis}

A statistical software program ${ }^{\dagger+}$ was used for all data analysis. The data were organized and presented as means \pm standard error. Prior to the initiation of this study, a power calculation was done to determine the sample size required. The estimated standard deviation of the measure-

\footnotetext{
**PerioGlas, USBiomaterials Corp., Alachua, FL
}

${ }^{*}$ Version 6.12, SAS Institute, Gary, IN. ment parameter was set at $0.7 \mathrm{~mm}$ The minimum detecting difference between pre- and post-treatment status was set at $1.0 \mathrm{~mm}^{44}$ With $\alpha$ set at 0.05 and the power of the study set at $95 \%$, a minimum number of 9 patients was required to allow a $95 \%$ chance of detecting a statistically significant difference. Analysis of the treatment effect at each time point (baseline, 3 months, 6 months, and 9 to 13 months reentry) was completed using the one-way repeated measures ANOVA for the normally distributed continuous parameters; e.g., attachment level, and Friedman's test for the non-normally distributed continuous parameters; e.g., mobility. Similar statistical methods were used for testing the hypothesis concerning time effect for each treatment group. The multivariate analysis was applied using the restricted/residual maximum likelihood (REML)-based random coefficient mixed effect model to adjust for the intra-correlation effect, treatment effect, time effect and the interaction effect between treatment and time. All tests of significance were 2-sided, and differences were considered statistically significant when $P$ $<0.05$.

\section{Examiner Calibration}

A patient with 2 contralateral intrabony defects and probing depths $\geq 6 \mathrm{~mm}$ with attachment loss was used to calibrate the examiner (MIK). The examiner evaluated the patient on 2 separate occasions, 10 days apart. Two sets of measurements were made at each visit, with a $45 \mathrm{mi}-$ nute lag-time between measurements. Probing depth and clinical attachment level were measured at 6 sites around each of 2 teeth. The automated probe was used to make the measurements and an acrylic stent was used as a reference for measurements. The intraexaminer correlation coefficient of the single calibrated examiner was 0.94 using the Pearson (parametric) correlation test.

\section{RESULTS}

Fourteen patients participated in this study. Of the 28 teeth selected, one site did not qualify at the time of surgery because a root fracture was noted on the involved tooth. Therefore, 14 teeth were treated as controls (flap debridement) and 13 teeth were treated as test sites (flap debridement plus BG). Reentry surgery was performed between 9 to 13 months from baseline. Patient demographic information is shown in Table 1.

Few postoperative complications were noted. Two of the BG treated sites initially developed a pebbled surface texture interproximally but this eventually disappeared. One control site developed an abscess at 1 week postsurgery. The patient was treated with amoxicillin $500 \mathrm{mg}$ t.i.d. for 7 days. The site healed without further complications.

There were no significant differences between the test and control groups at any time period for GI, PI, and mobility (Table 2 ). 
Table 1. Patient Information

\begin{tabular}{|c|c|c|c|c|c|}
\hline Patient & Gender & Age & $\begin{array}{c}\text { Debridemen } \\
\text { Only } \\
\text { (Control) }\end{array}$ & $\begin{array}{l}\text { Debridement }+ \\
\text { Bioactive Glass } \\
\text { (Test) }\end{array}$ & $\begin{array}{l}\text { Reentry } \\
\text { Time } \\
\text { (Months) }\end{array}$ \\
\hline 1 & F & 56 & $12 \mathrm{mb}$ & - & 9 \\
\hline 2 & M & 62 & $31 \mathrm{mb}$ & $18 \mathrm{mb}$ & 12 \\
\hline 3 & $\mathrm{~F}$ & 67 & $29 \mathrm{mb}$ & $12 \mathrm{ml}$ & 12 \\
\hline 4 & $M$ & 58 & $11 \mathrm{dl}$ & $8 \mathrm{ml}$ & 9 \\
\hline 5 & $\mathbf{M}$ & 47 & $4 \mathrm{dl}$ & $13 \mathrm{db}$ & 12 \\
\hline 6 & $M$ & 43 & $12 \mathrm{ml}$ & $5 \mathrm{ml}$ & 13 \\
\hline 7 & M & 42 & $31 \mathrm{mb}$ & $18 \mathrm{mb}$ & 11 \\
\hline 8 & M & 66 & $5 \mathrm{ml}$ & 9 mid-1 & 9 \\
\hline 9 & M & 44 & $19 \mathrm{dl}$ & $29 \mathrm{db}$ & 11 \\
\hline 10 & M & 44 & $18 \mathrm{db}$ & $31 \mathrm{db}$ & 12 \\
\hline 11 & M & 41 & $2 \mathrm{dl}$ & $15 \mathrm{dl}$ & 12 \\
\hline 12 & M & 41 & $4 \mathrm{ml}$ & $15 \mathrm{ml}$ & 13 \\
\hline 13 & $\mathrm{M}$ & 35 & $18 \mathrm{db}$ & $3 \mathrm{ml}$ & 12 \\
\hline 14 & $\mathrm{~F}$ & 40 & $12 \mathrm{mb}$ & $4 \mathrm{mb}$ & 9 \\
\hline
\end{tabular}

Table 2. Comparison of Clinical Parameters Between Control (flap debridement, $n=14$ ) and Test (flap debridement + BG, $n=13$ ) (reported as mean \pm standard error)

\begin{tabular}{lllll}
\hline $\begin{array}{l}\text { Parameters/ } \\
\text { Group }\end{array}$ & Baseline & 3 Months & 6 Months & $\begin{array}{c}\text { 9/13 Months } \\
\text { (reentry) }\end{array}$ \\
\hline GI & & & & \\
$\quad$ Control & $0.6 \pm 0.2$ & $0.5 \pm 0.2$ & $0.4 \pm 0.2$ & $0.6 \pm 0.2$ \\
$\quad$ Test & $0.6 \pm 0.2$ & $0.6 \pm 0.2$ & $0.4 \pm 0.2$ & $0.5 \pm 0.1$ \\
PI & & & & \\
$\quad$ Control & $0.6 \pm 0.1$ & $0.8 \pm 0.2$ & $0.4 \pm 0.2$ & $0.8 \pm 0.2$ \\
$\quad$ Test & $1.1 \pm 0.2$ & $0.8 \pm 0.2$ & $0.4 \pm 0.1$ & $1.1 \pm 0.2$ \\
Mobility & & & & \\
$\quad$ Control & $0.5 \pm 0.2$ & $0.9 \pm 0.1$ & $0.6 \pm 0.2$ & $0.4 \pm 0.2$ \\
$\quad$ Test & $0.5 \pm 0.2$ & $0.5 \pm 0.2$ & $0.6 \pm 0.2$ & $0.5 \pm 0.2$ \\
\hline
\end{tabular}

Table 3 lists the soft and hard tissue measurements at baseline and reentry. There were no statistically significant differences between test and control groups for any of the parameters measured at baseline or reentry.

With regard to soft tissue measurements, BG treated sites had significant changes in PD, CAL, and S/FGM when compared to baseline $(P<0.05$, Table 3$)$. Table 4 shows these changes to be $1.24 \pm 0.43 \mathrm{~mm}$ PD reduction, $0.87 \pm 0.38 \mathrm{~mm}$ CAL gain, and $0.7 \pm 0.3 \mathrm{~mm}$ recession.
The control group also experienced reduced PD, gain of CAL, and increased recession (S/FGM); however, the changes were not statistically significant (Table 3 ). The changes in PD, CAL, and S/FGM for the test group tended to be greater than for the controls, but the differences between groups were not significant (Table 4).

There were no significant differences between test and control groups for baseline and reentry hard tissue measurements (SB, CB, B-L defect width, and M-D defect width) (Table 3). The arithmetic determinations of vertical defect fill and crestal bone change are illustrated in Figure 2. Vertical defect fill was statistically significant $(P \leq$ $0.01)$ for control $(1.4 \pm 0.4 \mathrm{~mm})$ and test groups $(1.1 \pm$ $0.4 \mathrm{~mm}$ ) (Table 4). Even though there tended to be more defect fill for the controls than the test group, the difference between the groups was not statistically significant.

The difference between baseline and reentry values for SAC represent the amount of crestal resorption that occurred (Fig. 2). The test group exhibited $0.5 \mathrm{~mm}$ of mean crestal bone resorption while the control group exhibited $0.1 \mathrm{~mm}$ of mean crestal bone deposition. The difference between the groups was not statistically significant (Table 4).

Both groups had improvements in B-L defect width (test $=1.8 \pm 0.5 \mathrm{~mm}$, control $=0.6 \pm 0.6 \mathrm{~mm}$ ) and M$\mathrm{D}$ defect width (test $=1.6 \pm 0.6 \mathrm{~mm}$, control $=0.5 \pm$ $0.3 \mathrm{~mm}$ ). These changes were only significant for the test group $(P<0.05$, Table 3$)$. However, there was no significant difference between the test and control groups (Table 4).

There were no statistically significant differences noted between test and control groups for any parameter measured at baseline or reentry (Table 3). Furthermore, there were no significant differences between groups with regard to changes (improved, unchanged, or worsened) in clinical measurements from baseline to reentry (Table 4).

Table 5 shows the defect morphology in relation to the number of sites with $>50 \%$ or $<50 \%$ defect fill. Control sites had $>50 \%$ defect fill $36 \%$ of the time and test sites

Table 3. Clinical Measurements $(\mathrm{mm})$ for Control (flap debridement, $n=14$ ) and Test (flap debridement + BG, $n=13$ ) at Baseline and Reentry (reported as mean \pm standard error)

\begin{tabular}{|c|c|c|c|c|}
\hline \multirow[b]{2}{*}{ Measurement } & \multicolumn{2}{|c|}{ Control } & \multicolumn{2}{|c|}{ Test } \\
\hline & Baseline & Reentry & Baseline & Reentry \\
\hline \multicolumn{5}{|l|}{ Soft tissue } \\
\hline PD & $6.75 \pm 0.38$ & $6.07 \pm 0.42$ & $6.94 \pm 0.37$ & $5.70 \pm 0.37^{*}$ \\
\hline CAL & $9.62 \pm 0.31$ & $9.14 \pm 0.27$ & $10.35 \pm 0.60$ & $9.48 \pm 0.58 *$ \\
\hline S/FGM & $4.4 \pm 0.2$ & $4.9 \pm 0.3$ & $4.5 \pm 0.3$ & $5.2 \pm 0.4^{*}$ \\
\hline \multicolumn{5}{|l|}{ Hard tissue } \\
\hline SB & $12.1 \pm 0.6$ & $10.7 \pm 0.7 *$ & $11.7 \pm 0.6$ & $10.6 \pm 0.6^{*}$ \\
\hline B-L & $6.1 \pm 0.7$ & $5.4 \pm 0.7$ & $7.5 \pm 0.9$ & $5.6 \pm 0.8^{*}$ \\
\hline M-D & $3.2 \pm 0.3$ & $2.7 \pm 0.4$ & $3.9 \pm 0.7$ & $2.3 \pm 0.3 *$ \\
\hline SAC & $7.6 \pm 0.5$ & $7.4 \pm 0.6$ & $7.5 \pm 0.7$ & $8.1 \pm 0.6$ \\
\hline
\end{tabular}

*Statistically significant difference $(P<0.05)$ from baseline. $\mathrm{PD}=$ probing depth. $\mathrm{CAL}=$ Clinical attach ment level. S/FGM = stent to free gingival margin. $\mathrm{SB}=$ stent to base of defect. $\mathrm{B}-\mathrm{L}=$ bucco-lingual width. $\mathrm{M}-\mathrm{D}=$ mesio-distal width. $\mathrm{SAC}=$ stent to alveolar crest (calculated). 
Table 4. Clinical Changes $(\mathrm{mm})$ for Control (flap debridement, $n=14$ ) and Test (flap debridement $+\mathrm{BG}, \mathrm{n}=13$ ) Reentry (reported as mean \pm standard error)

\begin{tabular}{lccc}
\hline Measurement & Control & Test & Difference \\
\hline Soft tissue & & & \\
$\quad$ PD reduction & $0.68 \pm 0.35$ & $1.24 \pm 0.43$ & $-0.59 \pm 0.53$ \\
$\quad$ CAL gain & $0.48 \pm 0.42$ & $0.87 \pm 0.38$ & $-0.36 \pm 0.41$ \\
$\quad$ Increase gingival recession & & & \\
$\quad$ (S/FGM change) & $0.4 \pm 0.3$ & $0.7 \pm 0.3$ & $-0.3 \pm 0.3$ \\
Hard tissue & $1.4 \pm 0.4$ & $1.1 \pm 0.4$ & $0.4 \pm 0.6$ \\
$\quad$ Vertical defect fill & $0.6 \pm 0.6$ & $1.8 \pm 0.5$ & $-1.2 \pm 0.7$ \\
B-L defect fill & $0.5 \pm 0.3$ & $1.6 \pm 0.6$ & $-1.2 \pm 0.5$ \\
M-D defect fill & $-0.1 \pm 0.6$ & $0.5 \pm 0.4$ & $-0.6 \pm 0.7$ \\
Crestal resorption &
\end{tabular}

No statistically significant differences were found between the treatment groups.

Table 5. Defect Morphology in Relation to Percentage of Defect Fill of Control (flap debridement, $n=14$ ) and Test (flap debridement + BG, $\mathbf{n}=13$ ) Sites

\begin{tabular}{lccccc}
\hline & \multicolumn{2}{c}{ Control } & & \multicolumn{2}{c}{ Test } \\
\cline { 2 - 3 } \cline { 5 - 6 } $\begin{array}{l}\text { Defect } \\
\text { Morphology }\end{array}$ & $\begin{array}{c}\text { Defect Fill } \\
>50 \%\end{array}$ & $\begin{array}{c}\text { Defect Fill } \\
<50 \%\end{array}$ & & $\begin{array}{c}\text { Defect Fill } \\
>50 \%\end{array}$ & $\begin{array}{c}\text { Defect Fill } \\
<50 \%\end{array}$ \\
\hline 1 wall & 1 & 1 & & 0 & 0 \\
2 wall & 2 & 3 & & 2 & 4 \\
3 wall & 0 & 0 & & 1 & 1 \\
1-2 wall & 1 & 2 & & 0 & 2 \\
2-3 wall & 1 & 3 & & 0 & 3 \\
Total & 5 & 9 & & 3 & 10 \\
$\%$ & 35.7 & 64.3 & & 23.1 & 76.9 \\
\hline
\end{tabular}

had $>50 \%$ defect fill $23 \%$ of the time. Control sites had mean bone fill of $36.4 \%$ and test sites had mean bone fill of $27.9 \%$. There was no significant difference in the percentage bone fill between groups.

\section{DISCUSSION}

In this study, BG caused no adverse clinical side effects. Two test sites developed a pebbled surface texture during the first weeks after surgery. This eventually resolved to a normal surface texture. All other test sites healed uneventfully. One of the control sites developed an abscess at 1 week but it resolved with antibiotic treatment. The postoperative infection incidence was $0.07 \%$ (1 out of 14) for the control sites and $0 \%$ for the test sites. This compares favorably with Pack and Haber, who reported an infection rate of $<1.00 \%$ after periodontal surgery when no adjunctive antibiotics were prescribed. ${ }^{45}$

GI and PI scores for both our treatment groups were low (Table 2). There was little inflammation at the bioactive glass treated sites. In addition, no infections developed at the BG treated sites. This agrees with other reports that indicate $B G$ is biocompatible at the clinical and histologic level. . $33,34,35.39$

Treatment of intrabony defects with BG or debridement resulted in $\mathrm{PD}$ reduction (test $=1.24 \mathrm{~mm}$, control $=0.68$ $\mathrm{mm}$ ), gain of CAL (test $=0.87 \mathrm{~mm}$, control $=0.48 \mathrm{~mm}$ ) and increased recession (test $=0.7 \mathrm{~mm}$, control $=0.4$ $\mathrm{mm}$ ). These changes were greater for BG treated sites than debridement treated sites; however, the differences did not reach a level of statistical significance (Table 4). Our findings agree with the clinical findings reported by Zamet et al. ${ }^{39}$ In addition, they used computer aided densitometric image analysis (CADIA) and found signifcantly better bone density and volume $(P<0.001)$ in BG treated sites. This, however, could be attributed to unresorbed, non-incorporated BG particles in the defects. In the present study, granulation tissue containing BG particles often was curetted from defects at reentry.

PD reduction, CAL gain, recession, M-D defect fill, B$L$ defect fill, and vertical defect fill were statistically significant for the BG treated sites in this study $(P<0.05)$. For the control sites, however, only vertical defect fill was significant $(P<0.05)$. Studies that evaluated other alloplastic materials have reported greater $P D$ reduction (mean range 2.5 to $4.3 \mathrm{~mm}$ ) and CAL gain (mean range of 1.0 to $3.6 \mathrm{~mm}$ ) than we report here. ${ }^{17.46-50}$ The debridement-only groups in those studies yielded less PD reduction $(2.3$ to $3.4 \mathrm{~mm})$ and CAL gain $(0.7$ to $1.2 \mathrm{~mm})$ than the alloplast treated test sites. In this study, gingival recession averaged $0.7 \mathrm{~mm}$ for the test teeth and $0.4 \mathrm{~mm}$ for the control teeth. This is less recession than others reported for comparable alloplasts (grafted sites, 1.2 to $1.6 \mathrm{~mm}$ versus non-grafted sites -1.1 to $2.0 \mathrm{~mm}$ ). ${ }^{17.46 .48}$ Differences in measuring techniques may account for some of the variance in results. Many of the previous studies used conventional periodontal probes while we used an electronic probe. ${ }^{16.17 .46,47,49-51}$ Badersten et al. reported that using an electronic probe in conjunction with a stent decreases measurement error and reduces the variance of measuring CAL..$^{52}$ On the contrary, a recent study reported that intra- and inter-examiner reliability was better with manual probes than electronic probes. ${ }^{53}$ The main advantages of the electronic probe are that measurements can be made to the nearest $0.1 \mathrm{~mm}$ and the data are input directly to a computer. ${ }^{53}$

We made hard tissue measurements after flaps were elevated and defects were thoroughly debrided. Some of the graft material appeared to be firmly embedded within the granulation tissue. Most of this granulation tissue was 
removed with a curet until a firm bony base was reached. Some regenerated tissue may have been removed in the process. This may explain why debridement treated sites had greater defect fill than BG treated sites $(1.4 \mathrm{~mm}$ versus $1.1 \mathrm{~mm}$ ). The amount of vertical bone fill in each group was significant $(P \leq 0.01)$; however, the difference between groups was not statistically significant. Nine months may be too early to expect complete bone remodeling after bone grafting with BG. Zamet et al. found that even at 12 months there was a significant difference in the density of BG grafts and the surrounding bone. ${ }^{39}$ They suggested that bone remodeling may have been incomplete at that time. It is possible that we would have gained more defect fill if we had waited longer.

The mean percentage defect fill in this study was $36.4 \%$ for control sites and $27.9 \%$ for test sites. The difference between the groups was not statistically significant. In this study, $35.7 \%$ of control sites had $>50 \%$ defect fill while $23.1 \%$ of test sites had $>50 \%$ defect fill (Table 5). Furthermore, of the test teeth that initially had $2 / 3$ - or 3-walldefects, only $20 \%(1 / 5)$ had $>50 \%$ fill. In comparison, Sepe et al. reported that $63 \%$ of intrabony defects treated with DFDBA exhibited $>50 \%$ fill. ${ }^{4}$ Other studies that evaluated alloplastic grafting materials reported defect fill ranging from $47 \%$ to $67 \%$. $^{17,23.47 .49 .50}$

Defects in this study tended to be wider and not as deep as those reported in other studies. ${ }^{17.23}$ The average M-D defect width was $3.2 \pm 0.3 \mathrm{~mm}$ for controls and 3.9 $\pm 0.7 \mathrm{~mm}$ for test sites. The average initial defect depth was $4.5 \pm 0.4 \mathrm{~mm}$ for control and $4.2 \pm 0.3 \mathrm{~mm}$ the test sites. Thus, test sites were initially shallower and wider than the control sites. The initial differences in M-D defect width and defect depth, however, were not significant. Also, $71 \%(10 / 14)$ of the control and $63 \%(8 / 13)$ of the test sites were 1-wall, 1/2-wall combination or 2-wall defects. It is well known that less fill can be expected in defects with fewer remaining walls. ${ }^{2}$ As pointed out earlier, however, only $20 \%$ of the 3 -wall and $2 / 3$-wall combination defects that we grafted with BG achieved $>50 \%$ fill.

Finally, we used BG with a wide particle size range of 90 to $710 \mu \mathrm{m}$. Other studies that used alloplasts with narrower size ranges (425 to $625 \mu \mathrm{m}$; 16380 to $520 \mu \mathrm{m}^{47}$ and 340 to $540 \mu \mathrm{m}^{54}$ ) reported better mean defect fill and percentage defect fill in grafted versus non-grafted control sites. Schepers and Ducheyne found histologic evidence of enhanced bone repair when they used a narrow size range ( 300 to $355 \mu \mathrm{m}$ ) of BG particles. ${ }^{55}$ They suggested cells can migrate into spaces between uniformly sized graft particles to form new bone. In contrast, when a wide size range $(100$ to $710 \mu \mathrm{m})$ of particles was used, smaller graft particles filled the spaces between the larger ones. As a result, infiltration of the BG implant with new bone was hindered. ${ }^{55}$ Furthermore, Furusawa and Mizunuma, demonstrated bone growth in sinuses augmented with a narrow size range of $\mathrm{BG}$ particles ( 300 to $355 \mu \mathrm{m}$ ). ${ }^{56}$ On the contrary, Fucini et al., ${ }^{57}$ treated human intrabony periodontal defects with small $(250$ to $500 \mu \mathrm{m})$ and large $(850$ to $1000 \mu \mathrm{m})$ particles of DFDBA. They found no statistically significant difference in the amount of mean defect fill between the two particle size ranges.

Control sites gained crestal bone $(-0.1 \mathrm{~mm} \mathrm{CR})$ while test sites lost crestal bone $(0.5 \mathrm{~mm} \mathrm{CR})$ during this study (Table 4). These differences were not statistically significant. Other studies have reported more mean CR in nongrafted control groups (0.18 to $1.3 \mathrm{~mm}$ ) and less $\mathrm{CR}$ with grafted test groups ( -0.61 to $0.60 \mathrm{~mm}$ ). ${ }^{17,23,46-50}$ Wood et al. ${ }^{58}$ and Polson and Heij ${ }^{59}$ reported crestal resorption after full thickness flap surgery similar to what we report here for BG treated sites.

We found flap debridement, with the addition of intramarrow penetration, resulted in significant vertical bone fill. This corroborates similar positive results others have reported after flap debridement surgery..$^{59-61}$ Others, however, have reported minimal bone defect response after open flap debridement. ${ }^{17.23 .51 .62 .63}$ Significant differences in the defect selection criteria, methods of measurement, data analyses, and decisions to use reentry evaluation may account for some of the differences observed between these studies.

An interesting finding of this study was that soft tissue changes were not of the same magnitude as hard tissue changes. One would expect that the magnitude of change for CAL and defect fill would be similar but we found greater defect fill than CAL gain (Table 4). This was true for test and control groups. Rabalais et al. reported similar results. ${ }^{49}$ They suggested two reasons for the observed discrepancy. First, there may be variations in probe penetration through the soft tissues because of variations in probing force and tissue tone. ${ }^{64}$ Second, during the reentry surgeries all of the soft tissues are removed from the intrabony defects prior to making measurements. Because of this discrepancy between soft and hard tissue measurements, we feel that it is necessary to perform reentry surgeries or bone sounding to accurately assess regenerative treatment outcomes.

Limitations of this study include short duration, small sample size, and restrictions in defect selection. If the study had been longer, better results may have been obtained at the grafted sites. With a larger sample size, some of the differences between the groups may have reached a level of significance. In addition, the grafted sites may have had more dramatic changes had the initial defects been deeper and had at least 2 remaining walls. Hence, further studies of longer duration, with larger sample sizes, and more controlled defect selection are needed.

From this study, the following conclusions can be drawn: 1) Flap debridement and flap debridement plus BG both resulted in decreased PD and gain of CAL. These changes were only significant for the BG treated 
group ( $P<0.05)$. 2) Both treatments resulted in significant vertical defect fill $(P \leq 0.01)$. 3) Results at sites treated with BG did not differ significantly from sites treated with debridement alone. 4) Bioactive glass was well tolerated by human tissues. 5) Further studies are required to clarify the beneficial effects, if any, of bioactive glass in treating periodontal intrabony defects.

\section{Acknowledgments}

The authors wish to thank USBiomaterials, Alachua, Florida, for donating the bioactive glass grafting material used in this study. This project was supported by a grant from the University of Michigan Periodontics/Prevention/Geriatrics Graduate Student Research Fund and Alumni Gift Account.

\section{REFRENCES}

1. Bernard GM. Healing and repair of osseous defects. Dent Clin North Am 1991;35:469-477.

2. Hiatt WH, Schallhorn RG. Intraoral transplants of cancellous bone and marrow in periodontal lesions. J Periodontol 1973;44:194-208.

3. Dragoo MR, Sullivan HC. A clinical and histological evaluation of autogenous iliac bone grafts in humans: Part I. Wound healing 2 to 8 months. J Periodontol 1973;44:599-613.

4. Sepe WW, Bowers GM, Lawrence JJ, Friedlaender GE, Koch RW. Clinical evaluation of freeze-dried bone allografts in periodontal osseous defects. Part II. J Periodontol 1978;49:9-14.

5. Bowers GM, Chadroff B, Carnevale R, et al. Histologic evaluation of new attachment apparatus formation in humans. Part III. $J$ Periodontol 1989;60:683-693.

6. Urist MR, Strates BS. Bone morphogenetic protein. J Dent Res 1971;50:1392-1406.

7. Mellonig JT, Prewett AB, Moyer MP. HIV inactivation in a bone allograft. J Periodontol 1992;63:979-984.

8. Schwartz Z, Mellonig JT, Carnes DL Jr, et al. Ability of commercial demineralized freeze-dried bone allograft to induce new bone formation. J Periodontol 1996;67:918-926.

9. Shetty V, Han T. Alloplastic materials in reconstructive periodontal surgery. Dent Clin North Am 1991;35:521-530.

10. Boetto J, Freeman E. Histologic evaluation of durapatite in experimental periodontal defects. J Can Dent Assoc 1984;50:239-244.

11. Froum SJ, Kushner L, Scopp IW, Stahl SS. Human clinical and histologic responses to durapatite implants in intraosseous lesions. Case reports. J Periodontol 1982;53:719-725.

12. Jarcho M. Calcium phosphate ceramics as hard tissue prosthetics. Clin Orthop 1981;157:259-278.

13. Meffert RM, Thomas JR, Caudill RF. Hydroxyapatite implantation-clinical and histologic analysis of a treated lesion and speculations regarding healing phenomena. Int $J$ Periodontics Restorative Dent 1986;6(6):60-66.

14. Sapkos SW. The use of Periograf in periodontal defects. Histologic findings. J Periodontol 1986;57:7-13.

15. Chiroff $\mathrm{R}$, White E, Weber KN, Roy DM. Tissue ingrowth in Replamineform implants. J Biomed Mater Res 1975;9:29-45.

16. Kenney EB, Lekovic V, Elbaz JJ, Kovacvic K, Carranza FA Jr, Takei $\mathrm{HH}$. The use of porous hydroxylapatite implant in periodontal defects. II. Treatment of Class II furcation lesions in lower molars. $J$ Periodontol 1988;59:67-72.

17. Kenney EB, Lekovic V, Han T, Carranza FA Jr, Dimitrijevic B. The use of porous hydroxylapatite implant in periodontal defects. I. Clinical results after six months. J Periodontol 1985;56:82-88.

18. Carranza FA Jr, Kenney EB, Lekovic V, Talamante E, Valencia J,
Dimitrijevic B. Histologic study of healing of human periodontal defects after placement of porous hydroxylapatite implants. $J$ Periodontol 1987;58:682-688.

19. Stahl SS, Froum SJ. Histologic and clinical responses to porous hydroxylapatite implants in human periodontal defects. Three to twelve months postimplantation. J Periodontol 1987;58:689-695.

20. Baldock WT, Hutchens LH Jr, McFall WT Jr, Simpson DM. An evaluation of tricalcium phosphate implants in human periodontal osseous defects in two patients. $J$ Periodontol 1985;56:1-7.

21. Ganeles J, Listgarten MA, Evian CI. Ultrastructure of durapatiteperiodontal tissue interface in human intrabony defects. $J$ Periodontol 1986;57:133-140.

22. Kenney EB, Lekovic V, Sa Ferreira JC, Han T, Dimitrijevic B, Carranza FA Jr. Bone formation within porous hydroxylapatite implants in human periodontal defects. J Periodontol 1986;57:76-83.

23. Meffert RM, Thomas JR, Hamilton KM, Brownstein CN. Hydroxylapatite as an alloplastic graft in the treatment of human periodontal osseous defects. J Periodontol 1985;56:63-73.

24. Egelberg J. Regeneration and repair of periodontal tissues. J Periodont Res 1987;22:233-242.

25. Hench LL, Paschall HA. Direct chemical bond from bioactive glassceramic materials to bone and muscle. J Biomed Mater Res 1973;7: $25-42$.

26. Schepers EJG, De Clercq M, Ducheyne P. Histological and histomorphometrical analysis of bioactive glass and fiber reinforced bioactive glass dental root implants. J Oral Rehab 1988;15:473-487.

27. Piotrowski G, Hench LL, Allen WC, Miller GJ. Mechanical studies of bone bioglass interfacial bond. J Biomed Mater Res 1975;4:4761.

28. Hench LL, Paschall HA. Histochemical responses at a biomaterial's interface. J Biomed Mater Res Symp 1974;8:49-64.

29. Kudo K, Miyasawa M, Fujioka Y, et al. Clinical application of dental implant with root of coated bioglass: short-term results. Oral Surg Oral Med Oral Pathol 1990;70:18-23.

30. Hench LL, Stanley HR, Clark AE, Hall M, Wilson J. Dental applications of bioglass implants. In: Bonfield, W, Hastings, GW, Tanner, $\mathrm{KE}$, eds. Bioceramics Volume 4. Oxford: Butterworth-Heinemann Ltd; 1991: 231-238.

31. Kirsh ER, Garg AK. Postextraction ridge maintenance using the endosseous ridge maintenance implant (ERMI). Compend Continuing Educ Dent 1994;15:234-236.

32. Wang SA, Chen AY, Yu ZE, Huang ZJ, Wao YM. Alveolar ridge augmentation with bioactive glass ceramics: a histological study. $J$ Oral Rehab 1989;16:229-239.

33. Fetner AE, Low SB, Wilson J, Hench LL. Histological evaluation of Bioglass particulates in gingival tissue. $J$ Dent Res 1987;66(Spec. Issue):298(Abstr 1530)

34. Wilson J, Low SB. Bioactive ceramics for periodontal treatment: Comparative studies in the patus monkey. J Applied Biomat 1992;3: 123-129.

35. Fetner AE, Hartigan MS, Low SB. Periodontal repair using PerioGlas in nonhuman primates: Clinical and histologic observations. Compend Continuing Educ Dent 1994;15:932, 935-938.

36. Schepers EJ, Ducheyne P, Barbier L, Schepers S. Bioactive glass particles of narrow size range: A new material for the repair of bone defect. Implant Dent 1993;2:151-156.

37. Schepers EJ, De Clercq M, Ducheyne P, Kempeneers R. Bioactive glass particulate material as a filler for bone lesions. J Oral Rehab 1991;18:439-452.

38. Schepers EJ, Pinruethai P. A comparative study of bioactive glass and porous hydroxylapatite particles in periodontal bone lesions. In: Ducheyne P, Christiansen D, eds. Bioceramics Volume 6. Butterworth-Heinemann Ltd; 1993: 113-116.

39. Zamet JS, Darbar UR, Griffiths GS, et al. Particulate bioglass as a grafting material in the treatment of periodontal intrabony defects. $J$ Clin Periodontol 1997;24:410-418. 
40. Miller PO. Textbook of Periodontia. Philadelphia: The Blakeston Co.; 1938:91.

41. Löe H, Silness J. Periodontal disease in pregnancy. I. Prevalence and severity. Acta Odontol Scand 1963;21:533-551.

42. Silness $\mathbf{J}$, Löe H. Periodontal disease in pregnancy. II. Correlation between oral hygiene and periodontal condition. Acta Odontol Scand 1964;22:121-135.

43. Duckworth JE, Judy PF, Goodson JM, Socransky SS. A method for the geometric and densitometric standardization of intraoral radiographs. J Periodontol 1983;54:435-440.

44. Osborn JB, Stoltenberg JL, Huso B, Aeppli D, Pihlstrom B. Measurement variability in moderate periodontitis using a conventional and constant force electronic probe. J Periodontol 1992;63:283-298.

45. Pack $P$, Haber J. The incidence of clinical infection after periodontal surgery. J Periodontol 1983;54:441-443.

46. Meadows CL, Gher ME, Quintero G, Lafferty TA. A comparison of polylactic acid granules and decalcified freeze-dried bone allograft in human periodontal osseous defects. J Periodontol 1993;64: 103-109.

47. Yukna RA, Cassingham RJ, Caudill RF, et al. Six month evaluation of Calcitite (hydroxylapatite) ceramic in periodontal osseous defects. Int J Periodontics Restorative Dent 1986;6(3):35-45.

48. Yukna RA. Osseous defect responses to hydroxylapatite grafting versus open flap debridement. J Clin Periodontol 1989;16:398-402.

49. Rabalais ML Jr, Yukna RA, Mayer ET. Evaluation of durapatite ceramic as an alloplastic implant in periodontal osseous defects. I. Initial six month results. $J$ Periodontol 1981;52:680-689.

50. Krejci CB, Bissada NF, Farah C, Greenwell H. Clinical evaluation of porous and nonporous hydroxyapatite in the treatment of human periodontal bony defects. J Periodontol 1987;58:521-528.

51. Mellonig JT. Decalcified freeze-dried bone allograft as an implant material in human periodontal defects. Int J Periodontics Restorative Dent 1984;4(6):40-55.

52. Badersten A, Nilveus R, Egelberg J. Reproducibility of probing attachment level measurements. J Clin Periodontol 1984;11:475-485.

53. Khocht A, Chang K-M. Clinical evaluation of electronic and manual constant force probes. J Periodontol 1998;69:19-25.

54. Yukna RA, Harrison BG, Caudill RF, Evans GH, Mayer ET, Miller
S. Evaluation of durapatite ceramic as an alloplastic implant in periodontal osseous defects. II. Twelve month reentry results. $J$ Periodontol 1985;56:540-547.

55. Schepers EJG, Ducheyne P. Bioactive glass particles of narrow size range for the treatment of oral bone defects: a 1-24 month experiment with several materials and particle sizes and size ranges. $J$ Oral Rehab 1997;24:171-181.

56. Furusawa T, Mizunuma K. Osteoconductive properties and efficacy of resorbable bioactive glass as a bone grafting material. Implant Dent 1997;6:93-101.

57. Fucini SE, Quintero G, Gher ME, Black BS, Richardson AS. Small versus large particles of DFDBA in human intrabony periodontal defects. J Periodontol 1993;64:844-847.

58. Wood DL, Hoag FM, Donnenfeld OW, Rosenfeld ID. Alveolar crest reduction following full and partial thickness flaps. $J$ Periodontol 1972;43:141-144.

59. Polson AM, Heijl LC. Osseous repair in infrabony periodontal defects. J Clin Periodontol 1978;5:13-23.

60. Becker W, Becker BE, Berg L. Repair of intrabony defects as a result of open debridement procedures. Report of 36 treated cases. Int J Periodontics Restorative Dent 1986;6(2):8-21.

61. Renvert S, Badersten A, Nilveus R, Egelberg J. Healing after treatment of periodontal intraosseous defects. I. Comparative study of clinical methods. J Clin Periodontol 1981;8:387-399.

62. Froum SJ, Oritz M, Witkin RT, Thaler R, Scopp IW, Stahl SS. Osseous autografts: III. Comparison of osseous coagulum-bone blend implants with open curettage. J Periodontol 1976;47:287-294.

63. Stahl S, Froum S, Kushner L. Healing responses of human intraosseous lesions following the use of debridement, grafting and citric acid root treatment. II. Clinical and histologic observations: One year postsurgery. J Periodontol 1983;54:325-338.

64. Armitage GC, Svanberg GK, Löe H. Microscopic evaluation of clinical measurements of connective tissue attachment levels. J Clin Periodontol 1977;4:173-190.

Send reprint requests to: Dr. Hom-Lay Wang, University of Michigan, School of Dentistry, 1011 N. University Ave., Ann Arbor, MI 481091078. E-mail: homlay@umich.edu

Accepted for publication May 26, 1998. 